\title{
Proportionality and Incommensurability: A Response to Timothy Endicott
}

\author{
Ary Jorge Aguiar Nogueira \\ Universidade de São Paulo (USP), São Paulo, Brazil \\ Email: aryjorge@usp.br
}

How to cite this paper: Nogueira, A. J. A. (2021). Proportionality and Incommensurability: A Response to Timothy Endicott. Beijing Law Review, 12, 906-913. https://doi.org/10.4236/blr.2021.123046

Received: August 24, 2021

Accepted: September 15, 2021

Published: September 18, 2021

Copyright $\odot 2021$ by author(s) and Scientific Research Publishing Inc. This work is licensed under the Creative Commons Attribution International License (CC BY 4.0).

http://creativecommons.org/licenses/by/4.0/

\begin{abstract}
This essay critically analyzes Timothy Endicott's argument on the application of proportionality to the issue of the incommensurability between interests (or values) in the adjudication of human rights. The paper turns to two authors who addressed the same issue and are positioned on opposite sides of the proportionality debate: Stavros Tsakyrakis and Virgilio Afonso da Silva. The essay intends to highlight the main criticisms regarding the application of proportionality in the face of the issue of incommensurability between values and expose the main weaknesses of Endicott's argument. The methodology chosen is the critical literature review. At last, proportionality would act to hide the fact that judges would be making moral judgments disguised in a supposedly neutral language, which seems to present a broader picture of the issue. Recognizing the lack of a common metric for balancing human rights does not negate the fact that it would still be possible to relate them. Therefore, it seems more coherent to consider what is involved (interests, values, or rights) in a broader context, before the judgment.
\end{abstract}

\section{Keywords}

Proportionality, Incommensurability, Interests, Values, Human Rights

\section{Introduction}

This essay critically analyzes Endicott's (2014) argument on the application of proportionality to the issue of the incommensurability of interests (or values) in the adjudication of human rights. Therefore, in addition to the presentation of the central argument, this paper turns to two authors who addressed the same issue and are positioned on opposite sides of the proportionality debate: Tsakyrakis (2009) and da Silva (2011).

The essay intends to highlight the main criticisms regarding the application of 
proportionality in the face of the issue of incommensurability between values and expose the main weaknesses of Endicott's argument.

For the purposes of this work, the incommensurabilities between interests, values, and rights were treated in the same manner. This is attributed to the following reasons: first, because the authors themselves did not make the distinction, and second, because such a distinction would only add a new line of discussion, while not making any significant contribution to the central argument.

The conclusion of the work suggests that the issue of incommensurability between values gains greater relevance when proportionality is adopted as a method for adjudicating human rights. However, the proportionality taken in the sense of Alexy (2010) and his successors reduces the discussion to a comparison of results, masking the confrontation of substantive moral issues with a supposed objectivity.

Adopting an approach that involves greater moral reasoning would allow us to recognize that although some level of incommensurability persists in conflicting values, it would still be possible to associate the values, considering the multiple relationships between political and moral values.

\section{The Problem of Incomensurability in Endicott's Work}

The main objective, as pointed before, is to expose the main weaknesses of Endicott's (2014) argument. His central argument is that the judicial resolution of disputes involving incommensurabilities would not be a breach of the rule of law, as this would require judges to reconcile incommensurable interests.

Endicott (2014) understands proportionality as the last step of a set of criteria used to assess public decisions, in which the judge questions whether the contested measure could be considered a violation of the law, after comparing its impact on the protected interest in relation to the benefit of the pursuit of public objectives.

This highlights a general objection to the proportionality reasoning of judges, that Endicott (2014) terms as the "incommensurability problem." As there would be no rational basis for deciding one way over others, the result would represent a departure from the rule of law in favor of a rule decided arbitrarily by judges.

For Endicott (2014), the identification of a single criterion, such as the social importance of the conflicting interests, would not eliminate incommensurability, if the application of the criterion continued to depend on incommensurable considerations. Thereby, he distinguishes radical incommensurability (when there is no rational basis for comparing any two objects in each domain, with respect to a given property or properties) from vague incommensurability (in which some pairs of objects could be compared with respect to some property or properties while others cannot). According to Endicott (2014), the incommensurabilities between public and private interests, in cases involving human rights, need not be necessarily radical. 
Furthermore, we would need a system that authorizes judges to balance what cannot be balanced, and in this case, it would be important for judges to have the power to impose their judgment on other branches of government in the search for a compromise.

However, the moral dimension of human rights alone cannot justify judicial review of the decisions of other public authorities. Consequently, Endicott (2014) proposes an institutional premise, according to which the respect that all public authorities should have for certain human interests could be better guaranteed by a court independent of the state, that gives the judge the ability to assess how the objectives of public authorities would affect those interests.

In the conception of the institutional premise, Endicott (2014) observed the appeal to a certain type of conventionalism, that is, the belief that the nature of the law and its normative force would be founded on social practice (Macedo Jr., 2015). In a way, Endicott's (2014) proposal is that the courts would be able to better identify fundamental human rights, as opposed to decision-makers in the executive and legislative bodies, since the latter group could eventually violate these rights in their pursuit of public purposes.

Endicott (2014) also presents a discussion about possible and actual pathologies resulting from proportionality reasoning, proposing a typology divided into three pairs (depending on whether the distortion is in favor of the claimant or the public authority): proportionality spill over, uncertainty, or deference. However, he claims that if the institutional premise is maintained, there would be good reasons for a declaration of rights issued by the courts.

\section{Proportionality: An Assault on Human Rights?}

Tsakyrakis (2009) is responsible for the most direct criticism of the use of proportionality as a method of adjudicating human rights, denouncing it on the fact that its use would only be a new attempt to grant precision and objectivity to the decision-making mechanism.

Tsakyrakis (2009) adopts Alexy's (2010) classic three-step proportionality concept, pointing out that it would be in the last step, understood as proportionality in the strict sense, that the true balancing would occur.

For Tsakyrakis (2009) balancing is a powerful metaphor that intends to capture the method of decision of rights. The scale, as a symbol of justice, would not only express an ancient idea about judgments, but would also embody the idea of precision of the natural sciences.

In response to this, Tsakyrakis (2009) presents three criticisms of balancing. The first concerns the absence of a categorization of rights, while the second addresses the legitimacy of the judiciary to perform the balancing.

However, for Tsakyrakis (2009), the most effective criticism of balancing arises from the fact of assuming a common metric in the process of a balanced judgement. The metaphor of the scale would disappear due to the impossibility of measuring incommensurable values by introducing a common quantitative 
measure. In this sense, the only way to introduce this metric would be to resort to utilitarianism, assuming that all interests could ultimately be reduced to a common value, such as money, pleasure, or happiness.

Tsakyrakis (2009) argues that the belief in the "strong" modality of incommensurability would lead to total agnosticism regarding morality. Consequently, positioning himself alongside Waldron (1994), the author defends a "weak" incommensurability, that, although recognizing the lack of a common metric for balancing, would still permit the relating of values to one another. For Tsakyrakis (2009), this is exactly what John Rawls, Ronald Dworkin, or Robert Nozick referred to when they insisted on the lexical priority or precedence of basic freedoms, on rights as trump or side constraints.

Tsakyrakis (2009) also criticizes what he calls as the majority approach (a clear conventionalist argument), situating it at what he understands as one of the basic methodological principles of balancing: "the principle of generosity by definition," according to which, the interpreter would assume a broad definition of what can be considered an instance of the exercise of a certain right.

The interpreter's purpose would then be solely to assess whether a particular act or behavior will be included prima facie within the scope of a provision that protects, for example, freedom of expression or religion. Since the limit is not severe, the interpreter can be generous at the specification stage, confident that all crucial normative issues can be transferred to the balancing stage. However, this approach would pervert more than it would elucidate the adjudication of human rights, because we would no longer ask initially what is right or wrong in these cases.

This method would give rise to failures as it would not pay enough attention to the stage of specifying the items it intends to balance, contenting itself with a prima facie specification (Alexy, 2010) of the scope of a human right, or of the opposing public interest. Although it seems more inclusive, this approach would turn out to be superficial.

According to Tsakyrakis (2009), the adequate specification of the content of a human right would be guided by the understanding of its importance, involving an agreement on how we value the right, placing it in the constellation of other political and moral values. In other words, it would involve a good deal of moral reasoning, that is likely to be lost when the analysis in the first stage is insufficiently refined.

In this vein, the principle of generosity would notably fail by not being able to eliminate, at the first stage, interests and preferences fueled by what Tsakyrakis (2009) defines as illicit justifications, that would not only be less important than the law with which they would be in conflict, but also be incompatible with them. Thus, the balancing approach would reduce conflicts between rights or between rights and the common good to comparisons of relative weights, ignoring the blocking function of the justification of rights.

The fact is that the courts often use the language of balance and proportional- 
ity, while engaging in substantive moral reasoning. Thus, this reality would present difficulties to the supporters of balancing. The notion that there would be an inviolable core content implies a substantive moral assessment of what is right and wrong.

Accepting that this core content cannot be compromised under any circumstances dismisses the idea that the right at stake can be weighed against competing public interests. In other words, there would be no balancing in the first place. A court that assumes the existence of an absolute minimum for each right would no longer be concerned with questions of intensity and degree and, therefore, of proportionality.

The problem with the rhetoric of balancing, in the context of proportionality, would be the obscuring of the moral considerations that are at the heart of human rights issues. Tsakyrakis (2009) points out that it may even be that judges are concerned with moral differences, and therefore try to circumvent moral arguments, masking the reasoning in a neutral language. However, the best way to resolve such disagreements would be to bring them to light for open discussion.

\section{Comparing the Incommensurable}

On the other side of the debate is da Silva (2011), for whom incommensurability would not be an obstacle to the application of proportionality in the adjudication of human rights.

According to da Silva (2011), the criticisms would share a common core: the insistence on the incommensurability of constitutional rights as an expression of the fear that assumes a possible commensurability could lead to an exaggerated use of balancing, which, in turn, would lead to insufficient protection of these rights.

In response, da Silva (2011) argues that objections to balancing based on incommensurability have their roots in fallacious assumptions about the relationship between the following three central concepts: balancing, incommensurability, and incomparability.

Like Alexy (2010), da Silva (2011) starts from the concept of principles such as optimization requirements or norms, that would require that something be done to the greatest extent possible, given the legal and factual possibilities, subsequently pointing out that in the event of a collision, the balancing would appear as necessary to establish a precedence relationship.

Regarding incommensurability, he states that two or more things (values, goods, rights, or principles) would be incommensurable if there is no common measure that can be applied to all of them. According to him, this notion of incommensurability is the basis of the frequent objection to balancing since solving problems of competing principles through balancing would demand a comparison between them-and since there would be no common measure that can be applied to all of them-the result of this balancing would simply be the result of an irrational and totally subjective choice on the part of those responsible for 
the decision, usually a judge.

Thus, da Silva (2011) is dedicated to attacking what he calls as the three conceptual and terminological mistakes: 1) a supposed distinction between strong and weak incommensurability, 2) the distinction between incommensurability and incomparability, and 3) the indispensability of naming a covering value of choice, with reference to which a particular comparison will be made.

The distinction between strong and weak incommensurability, as already seen, has its roots in the work of Waldron (1994). Additionally, according to da Silva (2011), it would take great efforts in creating and justifying precedence relations between rights (or rights and policies), based on the idea of trump cards or a lexical precedence, that could be used to demonstrate the realization of a previous balance to establish a type of ranking among rights.

However, da Silva (2011) is not convinced that this process would be balancing, since, according to him, lexical precedence would be irreconcilable both with the idea of balancing and with the constitutional jurisprudence of several countries. The courts would consider the factual and legal possibilities of each concrete case-in other words, the same two rights can be classified in opposite ways in two different cases.

If a given freedom always prevails over other freedoms or over the public good, no one will truly weigh those rights against each other (or against the public good), regardless of the concrete factual and legal possibilities present in each case.

Additionally, da Silva (2011) discusses the issue of incommensurability versus incomparability, pointing out that if the former implies the latter, the idea of balancing principles would be impossible. Since balancing presupposes comparison and since there is obviously no single measurement unit applicable to principles, it would be impossible to evaluate them in the event of a collision. To demonstrate this, da Silva (2011) proposes a trivial example: would it be possible to compare Bach to Madonna? It would be absurd to claim that Bach's music is so many units better than Madonna's (or vice versa) as there is no unit to measure the quality of music-in other words, this type of comparison, although feasible, would involve incommensurable values.

Finally, da Silva (2011) states that to be rational, comparisons must include a covering value of choice. Additionally, the more precise the definition of the covering value, the greater is the possibility of a rational decision. In the previous example of the comparison between Bach and Madonna, the covering value could simply be the "quality of the music." However, the inaccuracy of the covering value makes such a comparison difficult. Thus, if the covering values were the "contribution to Western musical culture" or "suitability as dance music," the comparison would be much more accurate.

Therefore, the da Silva's (2011) central argument is that the thesis of incomparability between basic values would be unimportant. For him, comparing basic values would not only be possible, but necessary. Comparisons and balances 
would always be made between concrete alternatives and not between abstract values.

Balancing basic constitutional rights is not intended to compare abstract values but concerns the countless possibilities of protecting and assessing human rights in a concrete situation. It is measuring trade-offs in concrete situations, as indicated by Alexy (2010) in the "Balancing Law", according to which, "the greater the degree of non-satisfaction or detriment of a principle, the greater the importance of satisfying the other".

This possibility of measuring trade-offs would allow the comparison of the most basic values and rights in constitutional cases. Once the idea of comparing abstract values is abandoned and the idea of measuring trade-offs is embraced, balancing values and rights would end up being open to rational choice. However, to argue that this comparison would create commensurability would not mean that the principles have become necessarily commensurable in the abstract, that is, separate from a concrete situation, nor would this procedure involve valueless, purely logical reasoning and be immune to any subjective influence or moral consideration.

\section{Conclusion}

As mentioned before, the main objective of this essay is to present two of the most relevant criticisms made in relation to the applicability of the idea of proportionality in the face of the incommensurability between values, based on the proposal formulated by Endicott (2014).

It is observed that Endicott (2014) positions proportionality as an element arising from the system of the rule of law itself and that the incommensurability faced by the courts would not be radical-in other words, it would not imply the existence of an insurmountable obstacle to the comparison of values by judges.

Although the author undertakes an evident argumentative effort to reconcile balance, incommensurability between values, and the adjudication of human rights, his view finds itself as invalid, when analyzed more rigorously.

For Endicott (2014), the legal system itself would demand that judges reconcile immeasurable interests against the unspecified public purposes, through proportionality. However, accepting the inexorability of proportionality would mean disregarding those other forms of conflict resolution could equally be possible and even better in certain contexts.

In contrast, da Silva's (2011) conception that abstract incommensurability could always be resolved in a kind of process of comparison of concrete results (trade-offs), equally does not seem to be capable of definitively dispelling the criticism regarding the failure to confront the moral dilemmas that may be involved in the adjudication of human rights.

In this sense, the criticism formulated by Tsakyrakis (2009), that proportionality would act to hide the fact that judges would be making moral judgments disguised in a supposedly neutral language, seems to present a broader picture of 
the issue. Certainly, recognizing the lack of a common metric for balancing human rights does not negate the fact that it would still be possible to relate them. Therefore, it seems more coherent to consider what is involved (interests, values, or rights) in a broader context, before the judgment.

When proportionality is adopted as a problem-solving technique without the previous exhaustion of concepts, or according to the "generosity principle," as pointed out by Tsakyrakis (2009), the issue of comparability between values seems to be reduced to a renewed form of utilitarianism, with the results assuming a role of precedence.

Thus, an analysis that considers the law, placing it as part of a constellation involving other values (political/moral), can result in the finding that a determined core of values has an inviolable character. This certainly implies a substantive moral assessment of right and wrong that mere comparison presupposes.

Additionally, a supposed anchoring in the empirical reality of the courts (something present in both Endicott (2014) and da Silva (2011)) does not seem to be an adequate argument to validate proportionality in the adjudication of human rights. The appeal to conventionalism, that can be perceived in these authors' works, does not consider the fact that judges are still looking for the best justifications for their decisions, even when they are not visible (Macedo Jr., 2015).

The supposed objectivity that proportionality promises masks the fact that moral considerations are inexorable. Perhaps, the adjudication of human rights is the issue at which the legal operator is most required to consider issues of moral background, and although the metaphor of the balancing scale is extremely seductive in its apparent simplicity, certain moral issues cannot be reduced to a mere comparison of results.

\section{Conflicts of Interest}

The author declares no conflicts of interest regarding the publication of this paper.

\section{References}

Alexy, R. (2010). A Theory of Constitutional Rights. Oxford University Press. https://doi.org/10.2202/1938-2545.1042

da Silva, V. A. (2011). Comparing the Incommensurable: Constitutional Principles, Balancing and Rational Decision. Oxford Journal of Legal Studies, 31, 273-301. https://doi.org/10.1093/ojls/gqr004

Endicott, T. (2014). Proportionality and Incommensurability. In G. Huscroft, B. W. Miller, \& G. Webber (Eds.), Proportionality and the Rule of Law: Rights, Justification, Reasoning. Cambridge University Press.

Macedo Jr., R. P. (2015). Dworkin's Criticism of Conventionalism and Its Relevance: A Conceptual Criticism Scheme. Revista Direito, Estado e Sociedade, 47. https://revistades.jur.puc-rio.br/index.php/revistades/article/view/602

Tsakyrakis, S. (2009). Proportionality: An Assault on Human Rights? International Journal of Constitutional Law, 7, 468-493. https://doi.org/10.1093/icon/mop011

Waldron, J. (1994). Vagueness in Law and Language: Some Philosophical Issues. California Law Review, 82, 509. https://doi.org/10.2307/3480971 